\title{
Antiinflammatory and Antinociceptive Activities of Zingiber zerumbet Methanol Extract in Experimental Model Systems
}

\author{
Z.A. Zakaria A.S. Mohamad C.T. Chear Y.Y.Wong D.A. Israf M.R. Sulaiman \\ Department of Biomedical Science, Faculty of Medicine and Health Sciences, University Putra Malaysia, Selangor, \\ Malaysia
}

\section{Key Words}

Zingiber zerumbet $\cdot$ Methanol extract $\cdot$ Antiinflammatory activity · Antinociceptive activity

\begin{abstract}
Objective: The present study was carried out to determine the antiinflammatory and antinociceptive activities of a methanol extract of Zingiber zerumbet rhizomes (MEZZ) using various experimental model systems. Materials and Methods: The MEZZ was prepared by macerating ovendried $\left(50^{\circ} \mathrm{C}\right)$ powdered rhizomes $(1.2 \mathrm{~kg})$ of $Z$. zerumbet in $80 \%$ methanol in a ratio of 1:20 (w/v) for $48 \mathrm{~h}$. The supernatant was collected, filtered and evaporated to dryness under reduced pressure $\left(50^{\circ} \mathrm{C}\right)$ yielding approximately $21.0 \mathrm{~g}$ of the crude dried extract. The crude dried extract was stored at $-20^{\circ} \mathrm{C}$ prior to use and was dissolved in normal saline $(0.9 \%$ $\mathrm{NaCl})$ immediately before administration at concentrations required to produce doses of 25, 50 and $100 \mathrm{mg} / \mathrm{kg}$. Results: All dosages of MEZZ showed significant $(p<0.05)$ antiedema activity when assessed using the carrageenan-induced paw edema test and the cotton-pellet-induced granuloma test. The MEZZ exhibited significant $(p<0.05)$ antinociceptive activity when assessed by the writhing, hot plate and formalin tests. Pretreatment with naloxone $(5 \mathrm{mg} / \mathrm{kg})$ significantly decreased the latency of discomfort produced by the $100 \mathrm{mg} /$
\end{abstract}

kg dose of MEZZ in the hot plate test. Conclusion: MEZZ produced antiinflammatory and antinociceptive activities which may involve the inhibition of bradykinin-, prostaglandin-, histamine- and opioid-mediated processes.

Copyright $\odot 2010$ S. Karger AG, Basel

\section{Introduction}

The association between inflammation and nociception has previously been reported [1]. During the inflammatory process, sensitizing and activating mediators (i.e. prostaglandins, histamine, kinins, etc.) target receptors on primary afferent nerve fibers involved in pain processing. The activated mechanoinsensitive 'sleeping' nociceptors then transmit the response to the spinal cord where the noxious input can induce central sensitization to pain. Based on this association, Attaway and Zaborsky [2] claimed that agents with antiinflammatory activity, either derived from animals or plants, can also possess an antinociceptive activity, which is supported by various findings [3-5].

The quest for new antiinflammatory and antinociceptive compounds lacking side effects has continued, with researchers continuously and successfully isolating a variety of promising compounds from plant sources [3-5].

\section{KARGER \\ Fax +4161306 1234 \\ E-Mail karger@karger.ch}

www.karger.com
(C) 2010 S. Karger AG, Basel

1011-7571/10/0194-0287\$26.00/0

Accessible online at:

www.karger.com/mpp
Prof. Dr. M. Roslan Sulaiman

Department of Biomedical Science, Faculty of Medicine and Health Sciences University Putra Malaysia

43400 UPM Serdang, Selangor (Malaysia)

Tel. +60 38947 2604, Fax +60 38947 2585, E-Mail mrs@ medic.upm.edu.my 
One of the fascinating plants that we are studying in our laboratory is Zingiber zerumbet Smith. It is a wild ginger belonging to the tropical and subtropical family of Zingiberaceae, originating in Southeast Asia. It has been cultivated for thousands of years as a spice and also for medicinal purposes, i.e. as a cure for headaches, swelling, colds, ulcers, sores and loss of appetite, nausea and even menstrual discomfort, and has been introduced to many parts of the world [6-9] as a rich source of compounds of phytomedicinal interest. According to Altman and Marcussen [10] and Jaganath and $\mathrm{Ng}$ [11], the rhizome of $Z$. zerumbet has been used to treat various ailments in Asian (including Malaysian and Indian) and Arabic traditional medicine since ancient times. In the Western world, $Z$. zerumbet is used in herbal medicinal practice for the treatment of rheumatological conditions and muscular discomfort $[12,13]$. Z zerumbet, also known as lempoyang by the Malays, has been reported to possess antiinflammatory, antioxidant and antimicrobial properties [14-16]. Furthermore, the juice of boiled $Z$. zerumbet rhizomes has also been used for the treatment of worm infestation in children. According to Jantan et al. [17] and Tan et al. [18], the methanol extract of $Z$. zerumbet (MEZZ) possesses inhibitory effects on platelet-activating factor and against the Den 2 virus NS2B/NS3 protease activity, respectively.

The volatile oils of $Z$. zerumbet rhizomes, which possess antibacterial activity, have been reported to contain a cyclic sesquiterpene zerumbone (ZER) or 2,6,9humulatrien-8-one as the major component, as well as humulene and camphene [19]. Chien et al. [20] have isolated ZER together with 3-O-methyl kaempferol, kaempferol-3-O-[2,4-di-O-acetyl-a-L-rhamnopyranoside] and kaempferol-3-O-[3,4-di-O-acetyl-a-L-rhamnopyranoside] from MEZZ. Dai et al. [21] have reported earlier that ZER displayed HIV-inhibitory and cytotoxic activities, while Chien et al. [20] have demonstrated the potent inhibitory effect of ZER on nitric oxide and prostaglandin $\mathrm{E}_{2}\left(\mathrm{PGE}_{2}\right)$ production. Furthermore, ZER also suppressed colon cancer cell proliferation, induced apoptosis [22] and suppressed the generation of free radicals, the production of proinflammatory protein and the proliferation of cancer cells accompanied by apoptosis [23]. Despite the various pharmacological effects associated with the plant, the antinociceptive activity of methanol $Z$. zerumbet rhizome extracts has not yet been reported. The present study was aimed at determining the possible antiinflammatory and antinociceptive activities of MEZZ using various experimental models.

\section{Materials and Methods}

\section{Plant Material}

Z. zerumbet rhizomes were purchased from a local wet market in Chow Kit Road, Kuala Lumpur, Malaysia, and were identified by Mr. Shamsul Khamis, a botanist at the Institute of Bioscience, Universiti Putra Malaysia (UPM), Serdang, Selangor, Malaysia. A voucher specimen (SK 622/07) was deposited at the herbarium of the Laboratory of Natural Products, Institute of Bioscience, UPM, Malaysia.

\section{Preparation of the MEZZ}

The MEZZ was prepared by macerating oven-dried $\left(50^{\circ} \mathrm{C}\right)$ rhizomes of $Z$. zerumbet into powder form using a Waring blender and soaking the powder $(1.2 \mathrm{~kg})$ in $80 \%$ methanol in a ratio of $1: 20(\mathrm{w} / \mathrm{v})$ for $48 \mathrm{~h}$. The supernatant was collected and filtered using Whatman No. 1 filter paper and the remaining plant residue was discarded. The filtered supernatant was evaporated to dryness under reduced pressure $\left(50^{\circ} \mathrm{C}\right)$ and the weight of the crude dried methanol extract was measured (approx. $21.0 \mathrm{~g}$ ). The crude dried extract was kept at $-20^{\circ} \mathrm{C}$ prior to use and was dissolved in normal saline $(0.9 \% \mathrm{NaCl})$ immediately before administration at concentrations required to produce doses of 25,50 and $100 \mathrm{mg} / \mathrm{kg}$.

\section{Preparation of Drugs}

Acetylsalicylic acid (ASA), morphine sulfate, naloxone, bradykinin, prostaglandin $\left(\mathrm{PGE}_{2}\right)$, histamine, loratadine and $\mathrm{HOE} 140$ were purchased from Sigma Co. (St. Louis, Mo., USA) and dissolved in $0.9 \% \mathrm{NaCl}$ at the required dosage, chosen based on doseresponse studies carried out in our laboratory and in previous studies [3-5].

\section{Experimental Animals}

Male Balb/c mice (25-30 g; 5-7 weeks old) and Sprague-Dawley rats $(180-200 \mathrm{~g} ; 8-10$ weeks old), obtained from the Animal Source Unit, Faculty of Veterinary Medicine, UPM, were used in this study. All of the animals were kept at room temperature (27 $\pm 2{ }^{\circ} \mathrm{C} ; 70-80 \%$ humidity; 12-hour light/darkness cycle) in the Animal Holding Unit, Faculty of Medical and Health Sciences, UPM, for at least $48 \mathrm{~h}$ before use. Food and water were supplied ad libitum up to the beginning of the experiments. At all times, the mice and rats were cared for in accordance with current UPM principles and guidelines for the care of laboratory animals and the UPM ethical guidelines for investigations of experimental pain in conscious animals as adopted from Zimmermann [24].

The experimental animals were divided into 12 groups of 7 mice each $(\mathrm{n}=7)$ and subcutaneously received $0.9 \% \mathrm{NaCl}, 100$ $\mathrm{mg} / \mathrm{kg}$ ASA or MEZZ $(25,50$ and $100 \mathrm{mg} / \mathrm{kg}) 30 \mathrm{~min}$ prior to being subjected to the abdominal constriction or hot plate tests, respectively. On the other hand, the rats were divided into 16 groups of 7 rats each $(n=7)$. The first batch of 6 groups of rats was used in the formalin test and subcutaneously received $\mathrm{NaCl}, 100 \mathrm{mg} /$ $\mathrm{kg}$ ASA, $5 \mathrm{mg} / \mathrm{kg}$ morphine or $\operatorname{MEZZ~}(25,50$ and $100 \mathrm{mg} / \mathrm{kg})$, respectively, $30 \mathrm{~min}$ prior to being subjected to the test. The second and third batches of 5 groups of rats were used in the carrageenaninduced and cotton-pellet-induced inflammation studies, and subcutaneously received $\mathrm{NaCl}, 100 \mathrm{mg} / \mathrm{kg}$ ASA or $\operatorname{MEZZ~(25,~} 50$ and $100 \mathrm{mg} / \mathrm{kg}$ ), respectively, $30 \mathrm{~min}$ prior to performing the given test. All of the test solutions were administered in a volume of $10 \mathrm{ml} / \mathrm{kg}$ body weight. 


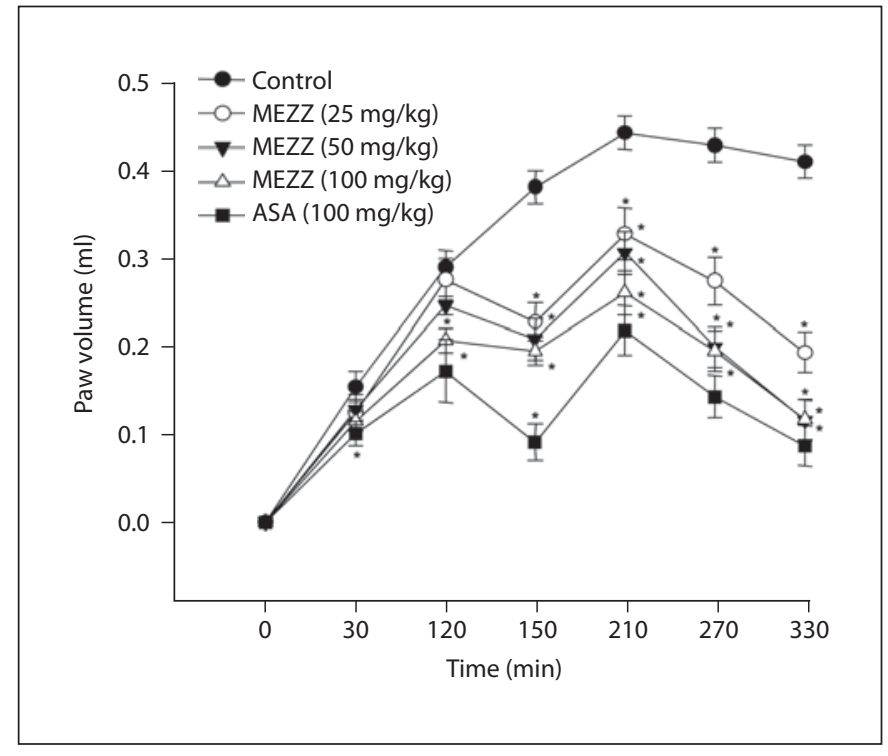

Fig. 1. The antiinflammatory profile of the MEZZ assessed by the carrageenan-induced paw edema test in rats. ${ }^{*} \mathrm{p}<0.05$ significantly different from control group.

\section{Antiinflammatory Assay}

Carrageenan-Induced Paw Edema Test. The carrageenan-induced paw edema test, considered as a model of acute inflammation, was used to determine the antiinflammatory activity of the MEZZ against this type of inflammation [3].

Cotton-Pellet-Induced Granuloma Test. The cotton-pellet-induced granuloma test, considered as a model of chronic inflammation, was used to determine the antiinflammatory activity of the MEZZ against this type of inflammation [4].

\section{Antinociceptive Assay}

Abdominal Constriction Test. The abdominal constriction test was used to determine the involvement of peripheral mechanisms in the antinociceptive activity of the MEZZ in a chemically induced nociceptive model [3].

Hot Plate Test. The $50^{\circ} \mathrm{C}$ hot plate test was used to study the involvement of central mechanisms in the antinociceptive activity of the MEZZ [3].

Formalin Test. The formalin test was used to evaluate the nonantiinflammatory, antinociceptive properties of the MEZZ [4]. The early phase, produced between 0 and 5 min after the administration of carrageenan, reflects neurogenic noninflammatory pain, while the late phase, occurring between 15 and 30 min after the carrageenan administration, indicates inflammation-mediated pain.

Preparation of Rat Ileum. The effect of the MEZZ on bradykinin-, $\mathrm{PGE}_{2-}$ and histamine-induced contraction of the isolated rat ileum was also determined according to the modified method of Roberts et al. [25]. Sprague-Dawley rats, starved of feed for $18 \mathrm{~h}$ but allowed free access to water, were killed by cervical dislocation. Part of the ileum (approx. $2 \mathrm{~cm}$ ), attached to the rear of the cecum, was removed and immediately placed

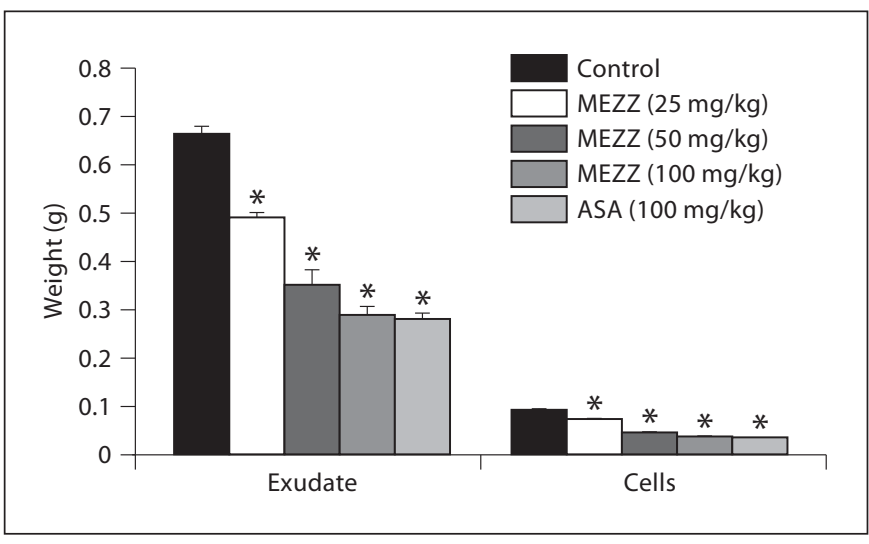

Fig. 2. The antiinflammatory profile of the MEZZ assessed by the cotton-pellet-induced granulomatous edema test in rats. Each column represents the mean weight of exudate (left panel) and cells (right panel) \pm SEM. ${ }^{*} \mathrm{p}<0.05$ significantly different from control group.

Table 1. Antinociceptive activity of MEZZ assessed by acetic acid-induced abdominal constriction test in mice

\begin{tabular}{lccc}
\hline & $\begin{array}{l}\text { Dose } \\
\mathrm{mg} / \mathrm{kg}\end{array}$ & $\begin{array}{l}\text { Number of } \\
\text { writhes }\end{array}$ & $\begin{array}{l}\text { Percent } \\
\text { inhibition }\end{array}$ \\
\hline Control (saline) & - & $120.3 \pm 10.2$ & - \\
MEZZ & 25 & $100.4 \pm 8.5$ & 16.7 \\
& 50 & $70.5 \pm 8.3^{1}$ & 41.7 \\
ASA & 100 & $54.4 \pm 8.1^{1}$ & 55.0 \\
& 100 & $44.3 \pm 6.3^{1}$ & 63.3 \\
\hline
\end{tabular}

Values are means \pm SEM unless stated otherwise. Number of animals in each group: $\mathrm{n}=7$.

${ }^{1}$ Values significantly different from control value at $\mathrm{p}<0.05$; ANOVA followed by post hoc analysis.

in a dish and covered with Krebs-Henseleit solution (composition in grams per liter in distilled water: $\mathrm{NaCl} 6.92, \mathrm{KCl} 0.35$, $\mathrm{KH}_{2} \mathrm{PO}_{4} 0.16, \mathrm{MgSO}_{4} 0.29, \mathrm{CaCl}_{2} 0.28, \mathrm{NaHCO}_{3} 2.1$ and glucose 2.1) at $37^{\circ} \mathrm{C}$. A dose-contractile response was obtained in the absence and presence of the MEZZ at concentrations of 2, 5 and $10 \mathrm{mg} / \mathrm{ml}$. Loratadine $(15 \mu \mathrm{g} / \mathrm{ml})$, ASA $(50 \mu \mathrm{g} / \mathrm{ml})$ and HOE 140 $(6 \mu \mathrm{g} / \mathrm{ml})$ were used as antagonists against histamine, $\mathrm{PGE}_{2}$ and bradykinin, respectively.

\section{Statistical Analysis}

The results are presented as means \pm standard error of mean (SEM). The one-way ANOVA test with Dunnett's post hoc test was used to analyze and compare the data, with $\mathrm{p}<0.05$ considered as the limit of significance. 
Table 2. Antinociceptive activity of MEZZ assessed by hot plate test in mice

\begin{tabular}{|c|c|c|c|c|c|c|c|c|c|c|}
\hline & \multirow{2}{*}{$\begin{array}{l}\text { Dose } \\
\mathrm{mg} / \mathrm{kg}\end{array}$} & \multicolumn{9}{|c|}{ Reaction time, $\mathrm{s}$} \\
\hline & & pretreatment & $30 \mathrm{~min}$ & $60 \mathrm{~min}$ & $90 \mathrm{~min}$ & $120 \mathrm{~min}$ & $150 \mathrm{~min}$ & $180 \mathrm{~min}$ & $210 \mathrm{~min}$ & $240 \mathrm{~min}$ \\
\hline Control (saline) & - & $5.7 \pm 0.2$ & $4.1 \pm 0.3$ & $4.6 \pm 0.3$ & $4.7 \pm 0.5$ & $4.7 \pm 0.6$ & $4.6 \pm 0.6$ & $4.5 \pm 0.3$ & $4.3 \pm 0.6$ & $3.6 \pm 0.2$ \\
\hline \multirow[t]{3}{*}{ MEZZ } & 25 & $5.8 \pm 0.3$ & $4.8 \pm 0.4$ & $5.1 \pm 0.2$ & $5.7 \pm 0.4$ & $6.2 \pm 0.5$ & $5.1 \pm 0.8$ & $5.3 \pm 0.7$ & $4.2 \pm 0.4$ & $3.4 \pm 0.4$ \\
\hline & 50 & $5.6 \pm 0.2$ & $6.8 \pm 0.3^{1}$ & $7.1 \pm 0.5^{1}$ & $6.9 \pm 0.3^{1}$ & $7.6 \pm 0.6^{1}$ & $7.7 \pm 0.5^{1}$ & $7.5 \pm 0.7^{1}$ & $4.8 \pm 0.4$ & $3.3 \pm 0.5$ \\
\hline & 100 & $6.1 \pm 0.3$ & $7.1 \pm 0.6^{1}$ & $7.6 \pm 0.5^{1}$ & $8.8 \pm 0.9^{1}$ & $9.9 \pm 1.2^{1}$ & $7.7 \pm 0.5^{1}$ & $7.9 \pm 0.3^{1}$ & $6.6 \pm 0.9$ & $3.5 \pm 0.5$ \\
\hline Morphine & 5 & $6.0 \pm 0.4$ & $9.2 \pm 1.0^{1}$ & $11.2 \pm 0.7^{1}$ & $13.0 \pm 0.7^{1}$ & $9.4 \pm 1.1^{1}$ & $8.4 \pm 0.9^{1}$ & $6.9 \pm 1.2$ & $6.5 \pm 1.0$ & $4.1 \pm 0.4$ \\
\hline Naloxone + MEZZ & $5+100$ & $6.0 \pm 0.2$ & $6.1 \pm 0.3^{2}$ & $4.2 \pm 0.3^{2}$ & $4.4 \pm 0.3^{2}$ & $5.2 \pm 0.4^{2}$ & $5.7 \pm 0.6$ & $5.5 \pm 0.3$ & $5.1 \pm 0.4$ & $4.7 \pm 0.7$ \\
\hline Naloxone + morphine & $5+5$ & $6.0 \pm 0.3$ & $3.9 \pm 0.7^{3}$ & $4.7 \pm 0.5^{3}$ & $5.7 \pm 0.3^{3}$ & $5.0 \pm 0.7^{3}$ & $5.8 \pm 0.6^{3}$ & $5.8 \pm 0.6$ & $5.0 \pm 0.6$ & $4.8 \pm 0.3$ \\
\hline
\end{tabular}

Values denote means \pm SEM unless stated otherwise. Number of animals in each group: $\mathrm{n}=7$.

${ }^{1}$ Values significantly different from control value at $\mathrm{p}<0.05$; ANOVA followed by post hoc analysis.

${ }^{2}$ Values significantly different from the MEZZ $100 \mathrm{mg} / \mathrm{kg}$ value at $\mathrm{p}<0.05$; ANOVA followed by post hoc analysis.

${ }^{3}$ Values significantly different from the morphine $5 \mathrm{mg} / \mathrm{kg}$ value at $\mathrm{p}<0.05$; ANOVA followed by post hoc analysis.

Table 3. Antinociceptive activity of MEZZ assessed by formalin test in rats

\begin{tabular}{lcll}
\hline & $\begin{array}{c}\text { Dose } \\
\mathrm{mg} / \mathrm{kg}\end{array}$ & \multicolumn{2}{l}{ Duration of paw licking, s } \\
\cline { 3 - 4 } & & $0-5 \mathrm{~min}$ & $15-30 \mathrm{~min}$ \\
\hline Control (saline) & - & $26.1 \pm 1.2$ & $53.0 \pm 2.3$ \\
MEZZ & 25 & $19.1 \pm 1.1^{1}(26.8)$ & $35.1 \pm 1.8^{1}(33.7)$ \\
& 50 & $16.9 \pm 0.5^{1}(35.5)$ & $23.6 \pm 2.5^{1}(55.5)$ \\
ASA & 100 & $14.3 \pm 1.3^{1}(45.3)$ & $20.4 \pm 2.3^{1}(61.5)$ \\
Morphine & 100 & $24.1 \pm 3.2^{1}(7.7)$ & $17.6 \pm 2.6^{1}(66.9)$ \\
& 5 & $9.7 \pm 1.2^{1}(62.9)$ & $40.9 \pm 2.8^{1}(22.9)$ \\
\hline
\end{tabular}

Values denote means \pm SEM unless stated otherwise. Number of animals in each group: $n=7$. Figures in parentheses are percentages of inhibition.

${ }^{1}$ Values significantly different from control values at $\mathrm{p}<0.05$; ANOVA followed by post hoc analysis.

\section{Results}

The antiedematogenic profile of the MEZZ assessed using the carrageenan-induced paw edema test in rats is given in figure 1. All dosages of the MEZZ exhibited significant $(p<0.05)$ antiedema activity in a concentration-dependent manner with the 50 and $100 \mathrm{mg} / \mathrm{kg}$ doses of the MEZZ exhibiting activity at $90 \mathrm{~min}$ following their administration. However, the $25 \mathrm{mg} / \mathrm{kg}$ dose of the MEZZ demonstrated activity at 150 min following its administration. For all dosages used, the activity lasted until the end of the experiment (330-min interval) but was lower than that produced by the $100 \mathrm{mg} / \mathrm{kg}$ dose of ASA.

The antiinflammatory activity of the MEZZ as assessed using the cotton-pellet-induced granuloma test in rats is shown in figure 2. All dosages of the MEZZ significantly $(p<0.05)$ reduced the weight of exudates and granuloma tissues when compared with the control group (treated with $0.9 \% \mathrm{NaCl}$ ) in a dose-dependent manner. The $50 \mathrm{mg} / \mathrm{kg}$ dose of the MEZZ produced an approximately $50 \%$ reduction in the weight of exudates (47\% reduction) and granuloma tissues (52\% reduction). Interestingly, the $100 \mathrm{mg} / \mathrm{kg}$ dose of the MEZZ showed activity that was comparable to that of $100 \mathrm{mg} / \mathrm{kg}$ ASA.

The antinociceptive profile of the MEZZ as determined using the acetic acid-induced abdominal constriction test in mice is given in table 1. The MEZZ produced $(p<0.05)$ antinociceptive effects in a concentration-dependent manner with significant activity recorded at doses of $\geq 50 \mathrm{mg} / \mathrm{kg}$. The highest dose of the MEZZ (100 mg/kg) produced an approximately $50 \%$ antinociceptive effect, which was comparable to the degree of antinociception exhibited by a $100 \mathrm{mg} / \mathrm{kg}$ dose of ASA.

The antinociceptive profile of the MEZZ determined using the hot plate test in mice is shown in table 2 . The MEZZ again exhibited significant $(\mathrm{p}<0.05)$ antinociceptive activity in a dose-dependent manner with significant effects observed only at doses of $\geq 50 \mathrm{mg} / \mathrm{kg}$. The antinociceptive activity of the 50 and $100 \mathrm{mg} / \mathrm{kg}$ doses of the MEZZ was observed within a 30 - and 180 -min interval following their administration. Throughout the study, a 


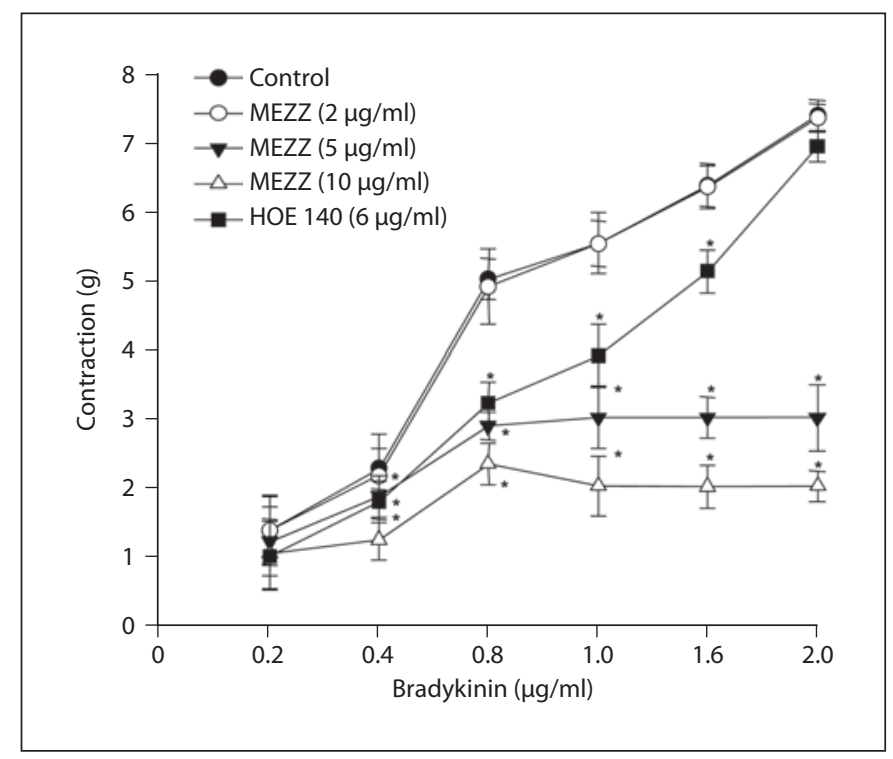

Fig. 3. The effects of the MEZZ on bradykinin-induced contraction of the isolated rat ileum preparation. Each point represents the mean of 6 observations. ${ }^{*} \mathrm{p}<0.05$ significantly different from control group.

$5 \mathrm{mg} / \mathrm{kg}$ dose of morphine produced greater antinociceptive activity than that of the MEZZ, and the activity of morphine was also observed at 30 and $180 \mathrm{~min}$ after the administration. Pretreatment with naloxone $(5 \mathrm{mg} / \mathrm{kg})$ significantly decreased the latency of discomfort induced by the MEZZ (100 mg/kg) when compared with the group receiving the same dose of extract alone.

The antinociceptive profile of the MEZZ determined using the formalin test in rats is given in table 3. Interestingly, the extract exhibited significant $(p<0.05)$ antinociception in both the early and late phases of nociception at all doses tested. The $100 \mathrm{mg} / \mathrm{kg}$ dose of the MEZZ exhibited approximately $50 \%$ antinociception in the early phase, while the $50 \mathrm{mg} / \mathrm{kg}$ dose demonstrated approximately $50 \%$ antinociception in the late phase of the test.

The effect of the MEZZ on bradykinin-induced rat ileum contraction is shown in figure 3 . The extract, at concentrations of 5 and $10 \mathrm{mg} / \mathrm{ml}$, caused a significant $(\mathrm{p}<0.05)$ reduction in bradykinin-induced contractions in a concentration-dependent manner and depressed the maximal responses to $59.2 \%$ (3.004 g) and $72.7 \%$ $(2.010 \mathrm{~g})$, respectively, as compared to the control value (7.371 g). Interestingly, the 5 and $10 \mathrm{mg} / \mathrm{ml}$ concentrations of the MEZZ exerted activity that was greater than that of $6 \mu \mathrm{g} / \mathrm{ml}$ of HOE 140 .

Antiinflammatory and Antinociceptive

Activities of Zingiber zerumbet

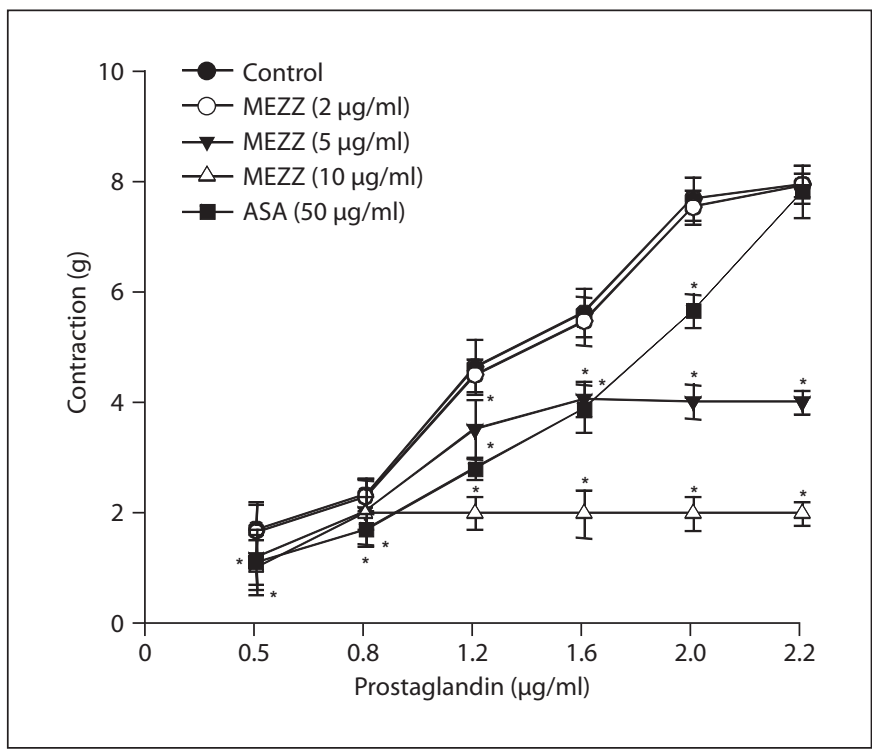

Fig. 4. The effects of the MEZZ on prostaglandin-induced contraction of the isolated rat ileum preparation. Each point represents the mean of 6 observations. ${ }^{*} \mathrm{p}<0.05$ significantly different from control group.

The effect of the MEZZ on $\mathrm{PGE}_{2}$-induced rat ileum contraction is shown in figure 4 . The MEZZ, at concentrations of 5 and $10 \mathrm{mg} / \mathrm{ml}$, caused significant $(\mathrm{p}<0.05)$ and concentration-dependent inhibition of tissue contraction. The percent inhibition of muscle contraction achieved after treatment with the 5 and $10 \mathrm{mg} / \mathrm{ml} \mathrm{MEZZ}$ doses was $49.5 \%$ (4.045 g) and 74.9\% (2.010 g), respectively, when compared to the control value $(8.015 \mathrm{~g})$. Similar to the bradykinin-induced contraction, 5 and $10 \mathrm{mg} /$ $\mathrm{ml}$ of MEZZ exhibited effects that were greater than that of $50 \mu \mathrm{g} / \mathrm{ml}$ ASA.

The effect of the MEZZ on histamine-induced rat ileum contraction is shown in figure 5 . The MEZZ, at concentrations of 5 and $10 \mathrm{mg} / \mathrm{ml}$, exerted a significant $(\mathrm{p}<$ $0.05)$ concentration-dependent inhibition of muscle contraction that shifted to the right with increasing concentrations of the MEZZ, as seen in the histamine dose-response curve, when compared to the control group. Interestingly, the $10 \mathrm{mg} / \mathrm{ml} \mathrm{MEZZ} \mathrm{dose} \mathrm{decreased} \mathrm{the} \mathrm{level}$ of contraction to below that produced by $15 \mu \mathrm{g} / \mathrm{ml}$ of loratadine at the beginning of the treatment using 1 and $2 \mu \mathrm{g} / \mathrm{ml}$ histamine concentrations. 


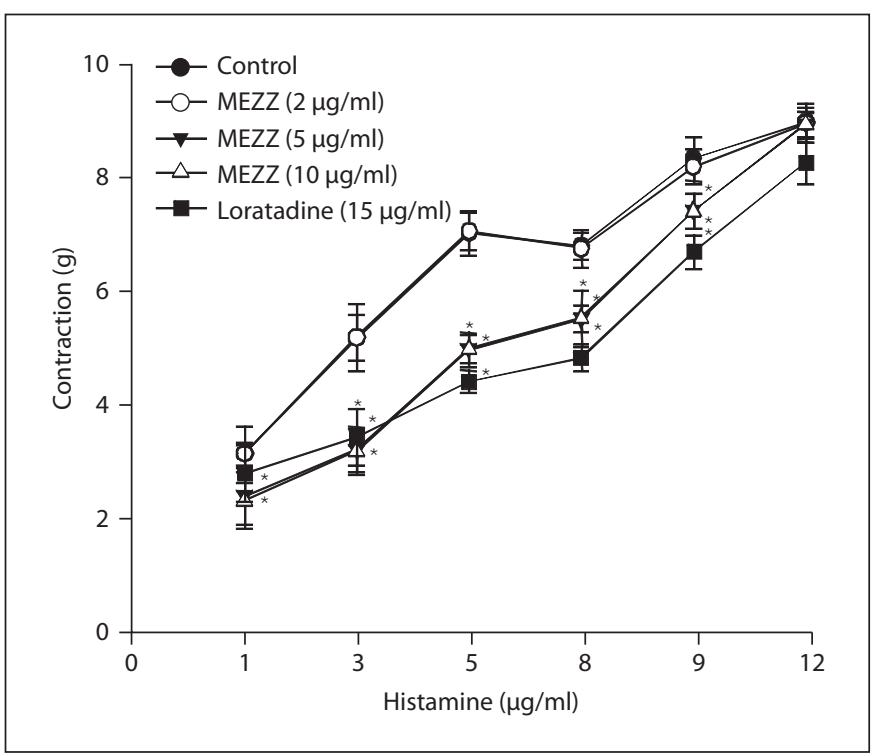

Fig. 5. The effects of the MEZZ on histamine-induced contraction of the isolated rat ileum preparation. Each point represents the mean of 6 observations. ${ }^{*} \mathrm{p}<0.05$ significantly different from control group.

\section{Discussion}

Z. zerumbet rhizomes are used as an antiinflammatory adjuvant for stomach ache, sprain and fever in many countries in Southeast Asia including Malaysia. The present study confirmed the antiinflammatory activity of the MEZZ from previous in vivo studies [14, 20]. We were also able to demonstrate the ability of the MEZZ to reverse both acute and chronic inflammation as assessed by the carrageenan-induced paw edema and cotton-pelletinduced granuloma tests, respectively. The MEZZ produced antinociceptive activity at the central and peripheral levels based on its inhibitory activity in the hot plate test and abdominal constriction test, respectively. Furthermore, the extract was effective in blocking chemically and thermally induced nociceptive effects, a characteristic of strong analgesics, e.g. opioid agonists [4]. The strong analgesic activity claimed was further supported by the findings that the MEZZ prolonged the latency to discomfort/pain in the hot plate test and inhibited nociception in both phases of the formalin test, as seen with many centrally acting analgesic drugs, e.g. morphine [26, 27]. In addition, Hosseinzadeh and Younesi [5] also claimed that any plant extract is considered to have centrally mediated analgesic activity if it demonstrates inhibitory activity in the abdominal constriction and hot plate tests. It is generally accepted that the peripherally acting analgesics such as nonsteroidal antiinflammatory drugs exert their antinociceptive activity only in the former test, while centrally acting analgesics such as opioid agonists exhibit their antinociceptive activity in both tests [5].

Several mechanisms of action could be suggested from the present study to explain the observed antinociceptive activity of the MEZZ. Prechallenging animals with naloxone, a nonselective opioid antagonist, leads to a reduction in the prolongation of nociceptive latency in the hot plate test by the MEZZ, indicating the involvement of the opioid receptor system in the mediation of the central antinociceptive activity of the MEZZ. Earlier, we had isolated ZER from the MEZZ and tested this compound for its antinociceptive activity using the abdominal constriction and hot plate tests. ZER was found to exhibit significant antinociceptive activity in both tests; this antinociceptive effect was completely abolished by pretreatment with $5 \mathrm{mg} / \mathrm{kg}$ of naloxone, indicating the involvement of opioid receptors in the mediation of the central antinociceptive activity of the MEZZ [28]. This pattern of activity was also seen with the MEZZ, suggesting the involvement of ZER in the antinociceptive effect of the extract. Interestingly, ZER has also been reported to exhibit antiinflammatory activity when assessed using the carrageenan-induced paw edema test [20] and could be suggested to partly contribute to the observed antiinflammatory activity of the MEZZ. The involvement of the cyclo-oxygenase-2 (COX-2) pathway, either at the peripheral and/or central levels, is also worth mentioning as part of the mechanism of action of the antinociceptive and antiinflammatory activities of the MEZZ. The acetic acid-induced abdominal constriction test has been associated with irritation of the peritoneal cavity, leading to the release of prostaglandins, e.g. $\mathrm{PGE}_{2}$ and $\mathrm{PGE}_{2} \alpha$, at peripheral sites, which contribute to inflammatory pain [29]. Thus, the ability of the MEZZ to inhibit/reverse the nociceptive response associated with this assay could suggest an action to inhibit peripheral actions of prostaglandins or COX-2. Although not yet proven, previous findings by Pini et al. [27] on the presence of central COX-2, and that its inhibition is involved in paracetamolinduced antinociceptive activity, seem to suggest the involvement of central COX-2 as part of the mechanism, together with the above-mentioned opioid system which may be responsible for the central antinociceptive activity of the MEZZ. Since ZER has been reported to be a constituent of the MEZZ [20,28], it is also worth mentioning that ZER suppresses the in vitro COX-2 expres- 
sion via a disruption of the stabilization of COX-2 mRNA $[30,31]$. Regarding the investigation of the extract's peripheral antinociceptive activity using the abdominal constriction test, ASA was chosen as the standard positive control instead of paracetamol despite its inhibitory effect on COX-2 because the former acts only peripherally [27], making it suitable for exploring the peripheral nociceptive effects seen by the abdominal constriction test [3]. The ability of paracetamol to enter the central nervous system [27] makes it an unsuitable positive control when assessing the extract's antinociceptive activity using the abdominal constriction test. In terms of the antiinflammatory activity of the MEZZ, the extract's ability to inhibit COX-2 and inducible nitric oxide synthase (iNOS) is postulated. This is based on a report indicating that carrageenan-induced edema formation involves mechanisms that include overexpression of COX-2 and iNOS [32]. Interestingly, iNOS has been known to be part of the processes involved in the development of pain/nociception $[30,33]$ and this could be one of the pathways involved in the antinociceptive action of the MEZZ. With regard to ZER as a major constituent of the MEZZ [20, $28]$, this compound has also been reported to inhibit in vitro nitric oxide production and iNOS expression, and $\mathrm{PGE}_{2}$ production, but it did not affect the level of the COX-2 protein [20]. Although ZER alone did not affect the COX-2 protein level, the fact that the MEZZ contains various types of compounds, i.e. 3-O-methyl kaempferol, kaempferol-3-O-[2,4-di-O-acetyl-a-L-rhamnopyranoside] and kaempferol-3-O-[3,4-di-O-acetyl-a-L-rhamnopyranoside], which could possibly affect the said enzyme, cannot be ruled out [20]. Furthermore, ZER and compounds such as 3-O-methyl kaempferol, which are found in the MEZZ [20], were shown to directly inhibit $\mathrm{PGE}_{2}$ production, and this could still explain the observed effects of the MEZZ on inflammation-mediated pain and the inflammatory process itself.

As described earlier, the antinociceptive activity of the MEZZ was attenuated by pretreatment with naloxone, a nonselective opioid antagonist. On this basis, we have suggested that $Z$. zerumbet exerts an opioid-like antinociceptive effect in mice. This finding is further supported by our recently published report on the opioid-like antinociceptive effect of ZER [28], which is believed to contribute to the overall antinociceptive effect of the MEZZ. We also present evidence that the MEZZ possesses inhibitory effects on inflammation and nociception at least partly by inhibiting bradykinin-, $\mathrm{PGE}_{2}$ - and histaminemediated actions. It appears that bradykinin-, histamineand $\mathrm{PGE}_{2}$-mediated inflammation/nociception path- ways are targets in the action of the MEZZ. Contraction of rat ileum induced by all three of the foregoing agonists was significantly inhibited by the MEZZ, suggesting that the ability of the MEZZ to interfere with the binding of these substances to their respective receptors may contribute to the attenuation of inflammation and nociception produced by these extracts [34]. Interestingly, the effect of the MEZZ on these agonist-induced contractions of rat ileum was consistent with a previous result by Kim et al. [34], who reported on an inhibitory effect of the methanol extract of the radix of Asarum sieboldii on bradykinin- and histamine-induced ileum contraction. However, we cannot rule out the possibility that the MEZZ could also inhibit signal transduction pathways downstream from the agonist-receptor binding.

Despite reports of the antiinflammatory activity of the ethanol and water extracts of $Z$. zerumbet against an acute model of inflammation that used the $\mathrm{PGE}_{2}$-induced paw edema test [14] and the antinociceptive activity of ZER [28], there are several new insights gained from the present study. These include the finding that MEZZ is able to attenuate carrageenan-induced acute inflammation as well as the chronic inflammation assessed by the cotton-pellet-induced granuloma test. Furthermore, we also report that the MEZZ can attenuate non-inflammation-mediated and inflammation-mediated pain, as seen in the respective early and late phases of the formalin test, which has never been reported on any extracts or compounds isolated from $Z$. zerumbet. Finally, in the present study, the MEZZ was shown to antagonize the contraction of rat ileum induced by several inflammatory mediators (i.e. bradykinin, $\mathrm{PGE}_{2}$ and histamine).

\section{Conclusion}

Our results suggest that the MEZZ possesses antiinflammatory and antinociceptive activities which may involve inhibition of bradykinin-, prostaglandin-, histamine- and opioid-mediated processes. Further studies extending these findings could lead to improvement in the currently available approaches for the treatment of ailments related to inflammation and pain.

\section{Acknowledgment}

This study was supported by the Research University Grant Scheme 2009 (04-01-09-0780RU/F1) from the UPM. 


\section{References}

$>1$ Roosterman D, Goerge T, Schneider SW, Bunnett NW, Steinhoff M: Neuronal control of skin function: the skin as a neuroimmunoendocrine organ. Physiol Rev 2006;86: 1309-1379.

2 Attaway DH, Zaborsky OR: Marine Biotechnology. Pharmaceutical and Bioactive Natural Products, ed 1. Spring Street, Plenum, 1993, vol 1, pp 1-23.

-3 Zakaria ZA, Loo YW, Abdul Rahman NI, Abdul Ayub AH, Sulaiman MR, Hanan Kumar G: Antinociceptive, anti-inflammatory and antipyretic properties of Bauhinia purpurea leaves aqueous extract in experimental animals. Med Princ Pract 2007;16:443-449.

4 Sulaiman MR, Zakaria ZA, Chiong HS, Lai SK, Israf DA, Azam Shah TM: Antinociceptive and anti-inflammatory effects of Stachytarpheta jamaicensis (L) Vahl (Verbenaceae) in experimental animal models. Med Princ Pract 2009; 18:272-279.

$>5$ Hosseinzadeh H, Younesi HM: Antinociceptive and anti-inflammatory effects of Crocus sativus L stigma and petal extracts in mice. BMC Pharmacol 2002;2:7.

$\checkmark 6$ Liang MH: From America: cookbook medicine or food for thought - practice guidelines development in the USA. Ann Rheum Dis 1992;51:1257-1258.

7 Awang DVC: Ginger. Can Pharm J 1992;125: 309-311.

-8 Grant KL, Lutz RB: Alternative therapies: ginger. Am J Health Syst Pharm 2000;57: 945-947.

$>9$ Park EJ, Pizzuto JM: Botanicals in cancer chemoprevention. Cancer Metastasis Rev 2002;21:231-255.

10 Altman RD, Marcussen KC: Effects of a ginger extract on knee pain in patients with osteoarthritis. Arthritis Rheum 2001;44:25312538.

11 Jaganath IB, Ng LT: Herbs. The Green Pharmacy of Malaysia. Kuala Lumpur, Vinpress and Malaysia Agricultural Research and Development Institute, 2000, pp 95-99.

$\checkmark 12$ Bordia A, Verma SK, Srivastava KC: Effect of ginger (Zingiber officinale Rosc) and fenugreek (Trigonella foenum graecum L) on blood lipids, blood sugar and platelet aggregation in patients with coronary artery disease. Prostaglandins Leukotr Essent Fatty Acids 1997;56:379-384.

13 Langner E, Greifenberg S, Gruenwald J: Ginger: history and use. Adv Ther 1998;15:2544.
14 Somchit MN, Nur Shukriyah MH: Anti-inflammatory property of ethanol and water extracts of Zingiber zerumbet. Indian J Pharmacol 2003;35:181-182.

15 Habsah M, Amran M, Mackeen MM, Lajis NH, Kikuzaki H, Nakatani H, Rahman A, Ghafar A, Ali AM: Screening of Zingiberaceae extracts for antimicrobial and antioxidant activities. J Ethnopharmacol 2000;72: 403-410.

16 Zaeoung S, Plubrukarn A, Keawpradub N: Cytotoxic and free radical scavenging activities of zingiberaceous rhizomes. Songklanakarin J Sci Technol 2005;27:799-812.

17 Jantan I, Rafi IAA, Jalil J: Platelet-activating factor (PAF) receptor-binding antagonist activity of Malaysian medicinal plants. Phytomedicine 2005;12:88-92.

18 Tan SK, Pippen R, Yusof R, Abdul Rahman NS, Ibrahim H, Khalid NZ: Screening of selected Zingiberaceae extracts for dengue-2 virus protease inhibitory activities. Sunway Acad J 2006;3:1-7.

19 Hasnah MS: Chemical constituents of some medicinal plants of Zingiberaceae: medicinal products from tropical rain forest. Proceedings of the Conference, Forest Research Institute Malaysia, Kuala Lumpur, 1991, pp 299-304.

20 Chien TY, Chen LG, Lee CJ, Lee FY, Wang CC: Anti-inflammatory constituents of Zingiber zerumbet. Food Chem 2008;110: 584-589.

21 Dai JR, Cardellina JHI, McMahon JB, Boyd MR: Zerumbone, an HIV-inhibitory and cytotoxic sesquiterpene of Zingiber aromaticum and $Z$ zerumbet. Nat Prod Lett 1997;10: 115-118.

22 Hoffman A, Spentner LM, Burke M: Redoxregulated mechanism may account for zerumbone's ability to suppress cancer cell proliferation. Carcinogenesis 2002;23:19611962.

23 Murakami A, Takahashi D, Kinoshita T, Koshimizu K, Kim HW, Yoshihiro A, Nakamura Y, Jiwajinda S, Terao J, Ohigashi $\mathrm{H}$ : Zerumbone, a Southeast Asian ginger sesquiterpene, markedly suppresses free radical generation, proinflammatory protein production, and cancer cell proliferation accompanied by apoptosis: the $\alpha, \beta$-unsaturated carbonyl group is a prerequisite. Carcinogenesis 2002;23:795-802.
24 Zimmermann M: Ethical guidelines for investigations of experimental pain in conscious animals. Pain 1983;16:109-110.

25 Roberts SJ, Papaioannou M, Evans BA, Summers RJ: Characterization of $\beta$-adrenoceptor mediated smooth muscle relaxation and the detection of mRNA for $\beta_{1^{-}}, \beta_{2^{-}}$and $\beta_{3}$-adrenoceptors in rat ileum. Br J Pharmacol 1999; 127:949-961.

-26 Chan TF, Tsai HY, Tian-Shang W: Anti-inflammatory and analgesic activities from the roots of Angelica pubescens. Planta Med 1995;61:2-8.

27 Pini LA, Vitale G, Ottani A, Sandrini M: Naloxone-reversible antinociception by paracetamol in the rat. J Pharmacol Exp Ther 1997;280:934-940.

-28 Sulaiman MR, Perimal EK, Zakaria ZA, Mokhtar F, Lajis NH, Israf DA: Preliminary analysis of the antinociceptive activity of zerumbone. Fitoterapia 2009;80:230-232.

29 Vogel HG, Vogel WH: Drug Discovery and Evaluation. Pharmacological Assays. Lewisville, JA Majors, 1997, pp 360-418.

30 Murakami A, Ohigashi H: Targeting NOX, iNOS and COX-2 in inflammatory cells: chemoprevention using food phytochemicals. Int J Cancer 2007;121:2357-2363.

31 Murakami A, Shigemori T, Ohigashi $\mathrm{H}$ : Zingiberaceous and citrus constituents, 1'acetoxychavicol acetate, zerumbone, auraptene and nobiletin, suppress lipopolysaccharide-inducced cyclooxygenase-2 expression in RAW264.7 murine macrophages through different modes of action. J Nutr 2005; 135(suppl):2987S-2992S.

32 Nishikori T, Irie K, Suganuma T, Ozaki M, Yoshioka T: Anti-inflammatory potency of FR167653, a p38 mitogen-activated protein kinase inhibitor, in mouse models of acute inflammation. Eur J Pharmacol 2002;451: 327-333.

33 Zakaria ZA, Sulaiman MR, Somchit MN, Mat Jais AM, Ali DI: The effects of L-arginine, D-arginine, L-NAME and methylene blue on Channa striatus-induced peripheral antinociception in mice. J Pharm Pharm Sci 2005;8:199-206

34 Kim SJ, Gao Zhang C, Taek Lim J: Mechanism of antinociceptive effects of Asarum sieboldii Miq radix: potential role of bradykinin, histamine and opioid receptor-mediated pathways. J Ethnopharmacol 2003;88: 5-9. 
